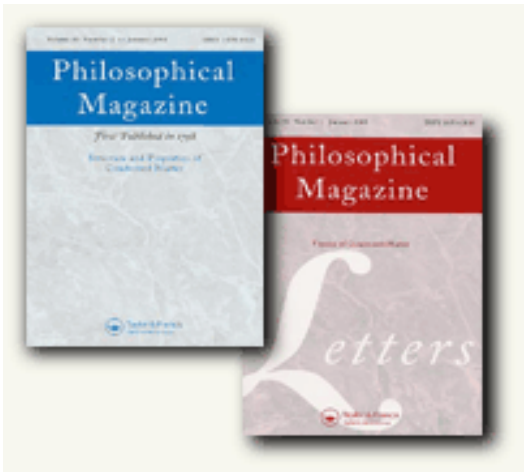

\title{
A new index to estimate the strain rate sensitivity of glassy polymers using conical/pyramidal indentation
}

\begin{tabular}{|r|l|}
\hline Journal: & Philosophical Magazine \& Philosophical Magazine Letters \\
\hline Manuscript ID: & TPHM-05-Oct-0471.R1 \\
\hline Journal Selection: & Philosophical Magazine \\
\hline Author: & 03-Mar-2006 \\
\hline Komplete List of Authors: & $\begin{array}{l}\text { Kermouche, Guillaume; LTDS UMR5513 CNRS/ECL/ENISE } \\
\text { Loubet, Jean-Luc; LTDS UMR5513 CNRS/ECL/ENISE } \\
\text { Bergheau, Jean-Michel; LTDS UMR5513 CNRS/ECL/ENISE }\end{array}$ \\
\hline Keywords (user supplied): & $\begin{array}{l}\text { polymers, indentation, mechanics of materials, mechanical } \\
\text { properties }\end{array}$ \\
\hline & viscoplasticity index, strain rate sensitivity \\
\hline \multicolumn{2}{|l}{} \\
\hline $\begin{array}{l}\text { Note: The following files were submitted by the author for peer review, but cannot be converted } \\
\text { to PDF. You must view these files (e.g. movies) online. }\end{array}$ \\
\hline Manuscript.TEX \\
\hline
\end{tabular}

\section{S ScholaroNE \\ Manuscript Central}




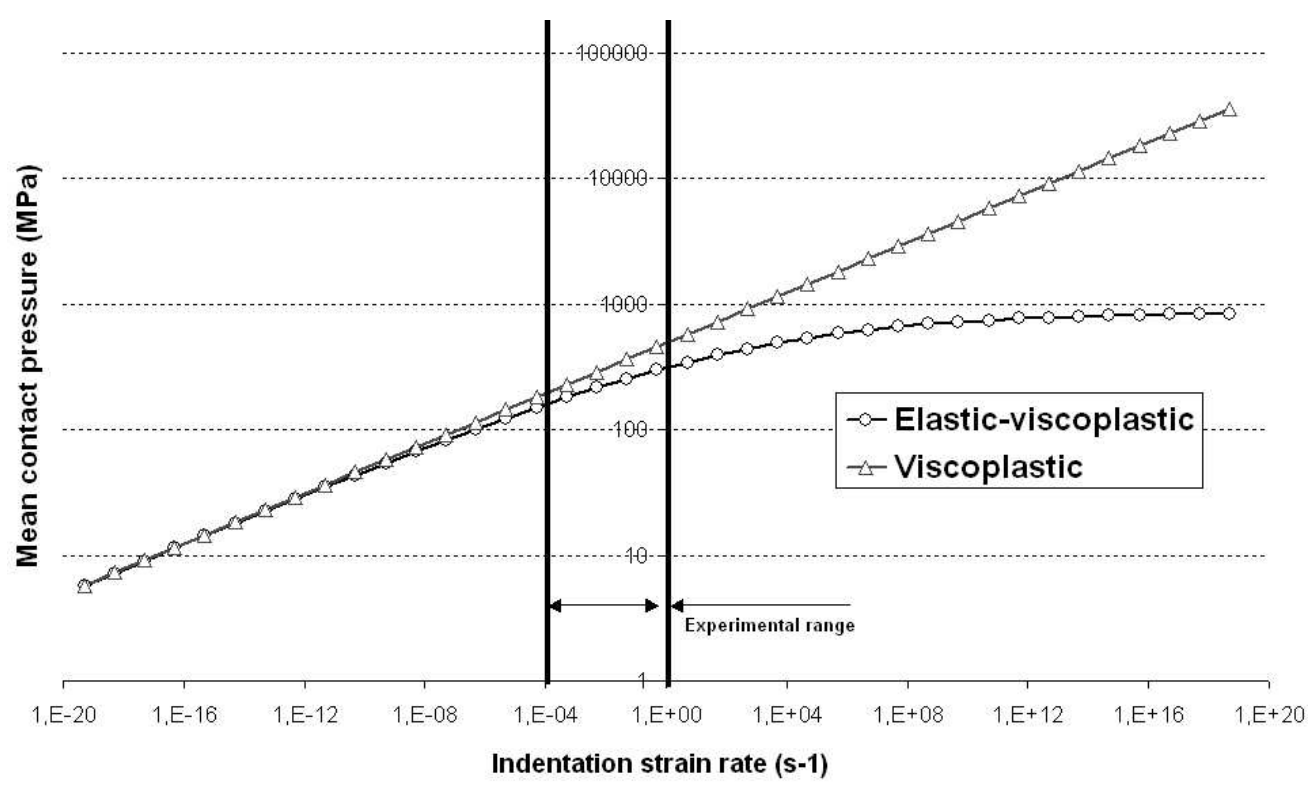

$337 \times 199 \mathrm{~mm}(72 \times 72 \mathrm{DPI})$ 


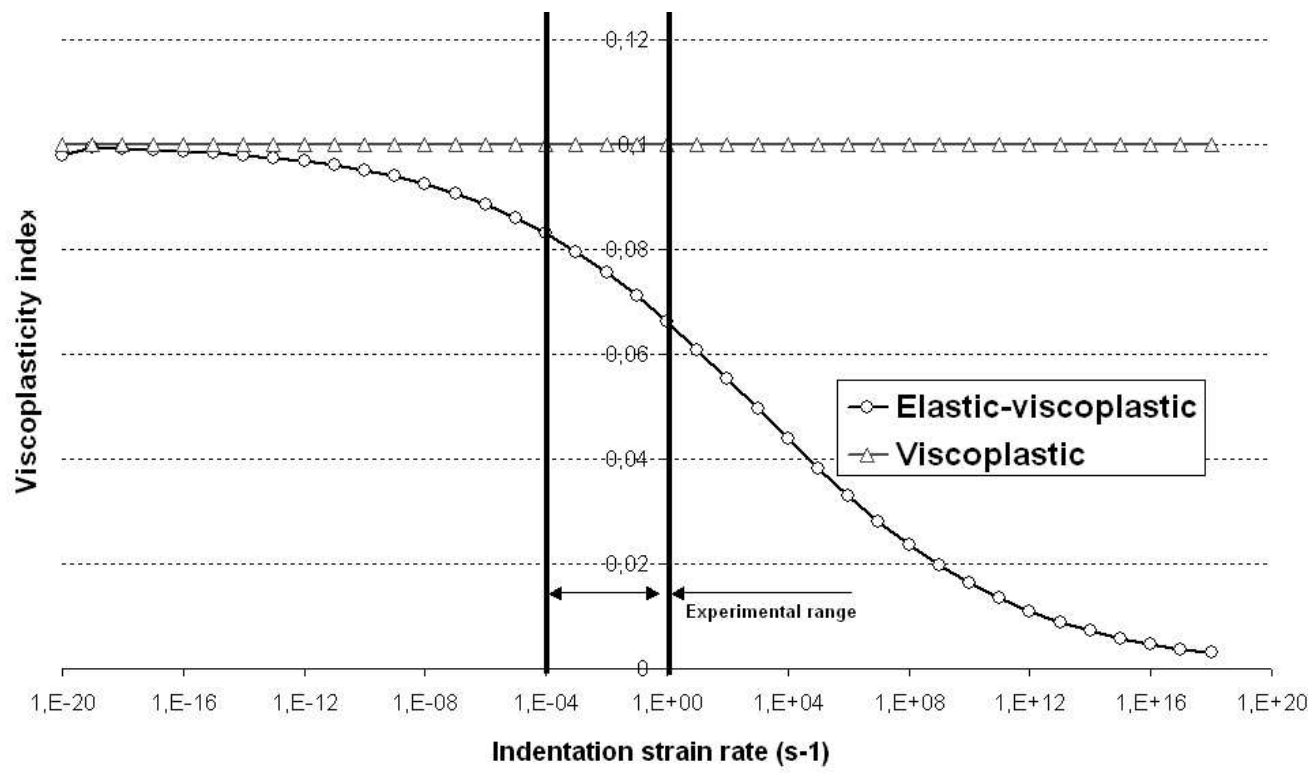

$337 \times 197 \mathrm{~mm}(72 \times 72$ DPI $)$ 


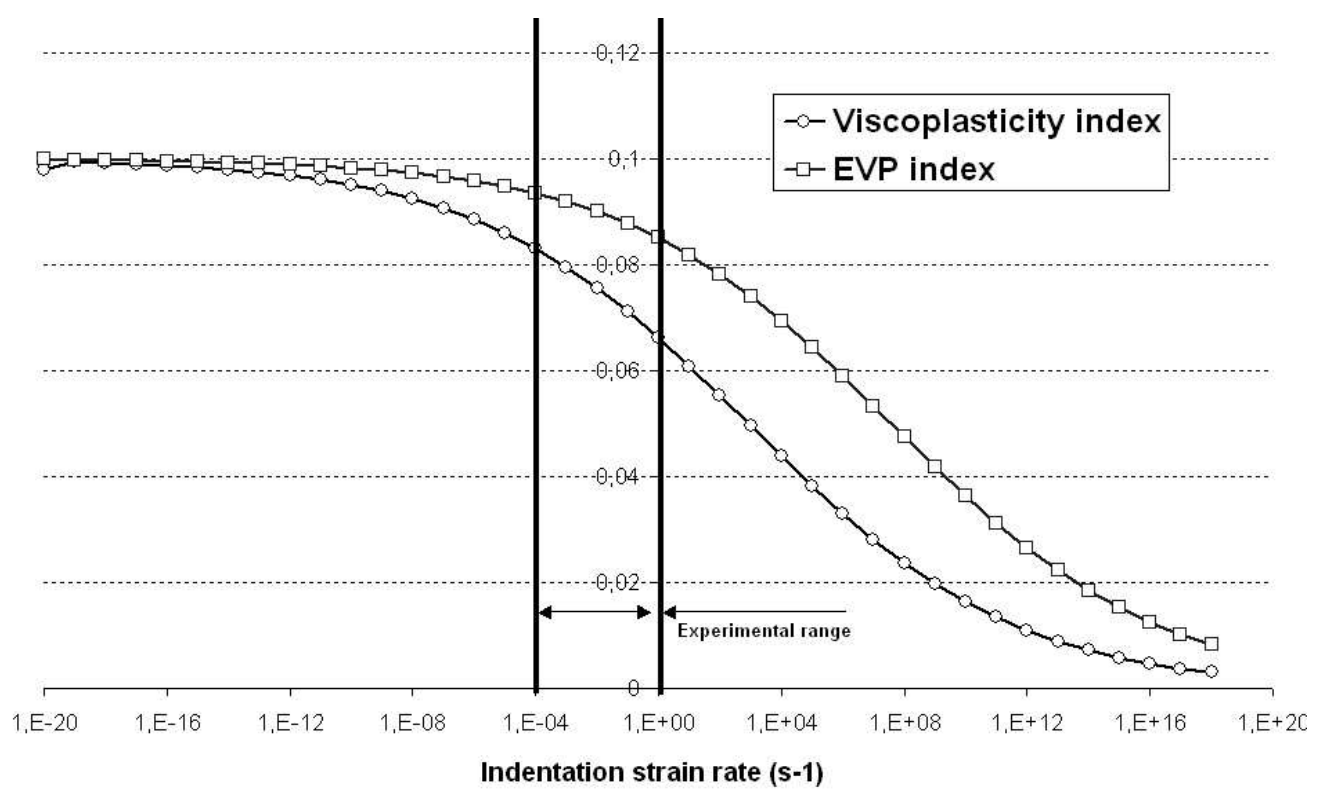

$332 \times 198 \mathrm{~mm}(72 \times 72$ DPI $)$ 

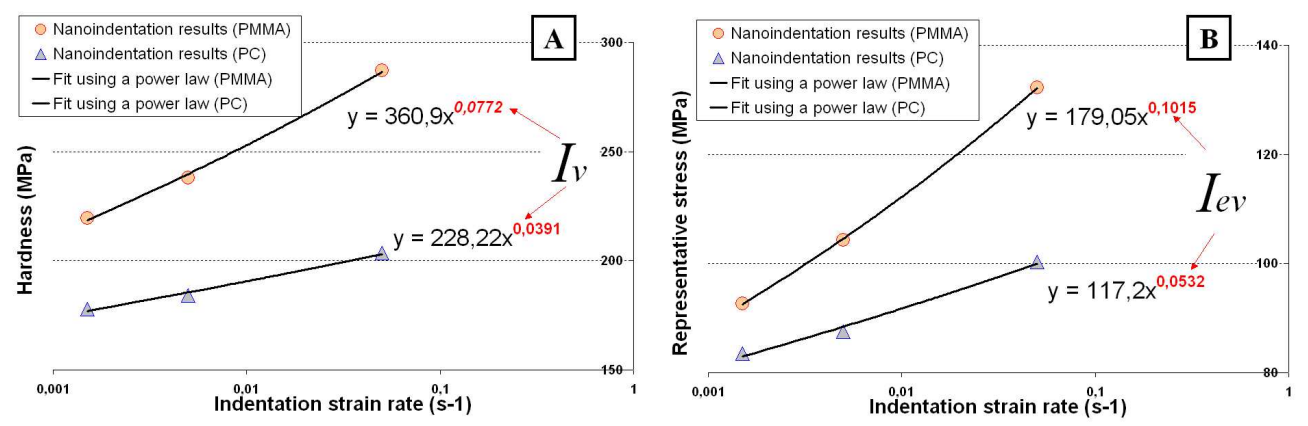

$241 \times 77 \mathrm{~mm}(200 \times 200 \mathrm{DPI})$ 


\title{
A new index to estimate the strain rate sensitivity of glassy polymers using conical/pyramidal indentation
}

\author{
G. Kermouche*, J.L. Loubet, J.M. Bergheau \\ Laboratoire de Tribologie et Dynamique des Systèmes, UMR 5513 CNRS/ECL/ENISE, \\ 58 rue J.Parot 42023 Saint Etienne Cedex 2, France \\ Corresponding author: guillaume.kermouche@enise.fr, Tel.:+33(0)4.77.43.84.61
}

\begin{abstract}
The increasing use of polymeric materials as thin coatings requires appropriate mechanical characterization methods taking account of time-dependent effects. A well-known result is that a constant indentation strain rate allows to determine the mechanical properties of such solids from indentation tests. To do that, most people assume a power law creep behavior and use the viscoplasticity index to determine the strain rate sensitivity. In the first part of this paper, we investigate the influence of the indentation strain rate on the hardness of power law creep solids and elastic-viscoplastic solids. It is shown that the assumption of power law creep solid is not sufficient to describe the behavior of polymeric materials in indentation. In the second part, we propose a new index, the EVP index, which gives a better approximation of the strain rate sensitivity than the viscoplasticity index. In the last part, we apply this method to nanoindentation tests on PMMA and polycarbonate samples.
\end{abstract}

Keywords: Cone indentation, Polymeric materials, Viscoplasticity index, Strain rate sensitivity

\section{Introduction}

The increasing use of polymeric materials as thin films deposited on substrates requires appropriate techniques of mechanical characterization. Obviously the conventional tensile test cannot 
be used to identify their mechanical properties in such conditions and, in recent years, the indentation technique has been developed for that purpose.

The indentation of isotropic elastoplastic material has been widely investigated over the past few years \{Tabor [1], Loubet et al [2], Hill et al [3], Dao et al [4], Cheng and Cheng [5]\} and many laws from experimental studies and simplified models have been proposed. Recently, the development of nanoindentation techniques has made it possible to finely characterize the mechanical properties of surfaces \{Oliver and Pharr [6], Loubet et al [7], Bec et al [8]\}. Tabor [1] and Hill [9] have pointed out that the real definition of hardness is the mean pressure under load and that the value of the hardness of ductile solids is essentially a measure of their plastic properties. They showed that the mean pressure can be related to the yield stress of the material by a simple factor which depends on the properties of the indented material and on the shape of the indenter. It was also shown experimentally that, for self-similar indenter \{conicalpyramidal tips , the indentation of elastoplastic materials follows the principle of geometric similarity. This principle gives a solid theoretical framework which has led to the development of many approximate solutions of elastoplastic indentation problems [10][11]. It is now possible to extract the yield stress and the strain hardening exponent of such solids.

However, currently available theories developed for time-independent materials cannot suitably be used to measure the mechanical properties of time-dependent materials such as polymeric materials. Indeed, the principle of geometric similiraty is not always satisfied. For power law creep solids, Lucas [12] has observed that the mean pressure is constant during the indentation test when indentation strain rate $\dot{h} / h$ is constant, where $\mathrm{h}$ is the penetration depth and, $\dot{h}$ the penetration rate. The same result has been obtained by Cheng and Cheng [5] with the help of a dimensional analysis. In a previous paper [13], we have shown that the principle of geometric similiraty is satisfied during cone indentation experiments of time dependent materials \{viscoelastic solids, elastic-viscoplastic solids\}, only if the indentation strain rate is constant. This result is of primary importance for glassy polymers for which the assumption of power law creep solids is not acceptable. Indeed, it is much appropriate to consider an elastic-viscoplastic behavior [14].

In the first part of this paper, we compare the effects of the indentation strain rate on the 
mean indentation pressure of power law creep solids and elastic-viscoplastic solids that follow the Bingham-Norton law [15]. Then, we explain that the viscoplasticity index [16], defined only for power law creep solids, does not equal to the strain rate sensitivity in the case of elastic-viscoplastic solids \{such as glassy polymer\}. We thus propose a new index, which allows to obtain a better estimation of the strain rate sensitivity than the viscoplasticity index. In the last part, we apply this method to nanoindentation experiments performed on PMMA and PC \{polycarbonate\}.

\section{The effects of the indentation strain rate on hardness values}

\subsection{Power law creep solids}

The assumption of power law creep behavior is very often well adapted to the modeling of anelastic time-dependent materials. The strain rate sensitivity of such materials can be described by a simple power law relation :

$$
\sigma=K \dot{\varepsilon}^{m}
$$

where $\sigma$ is the uniaxial stress and $\dot{\varepsilon}$ is the uniaxial strain rate. Consistency $K$ and strain rate sensitivity $m$ are materials constants. Cheng and Cheng [5] have shown using dimensional analysis that the mean indentation pressure is given by:

$$
p_{m}=\Pi_{\delta} K\left(\frac{\dot{h}}{h}\right)^{m}
$$

where $\Pi_{\delta}$ is a dimensionless function of strain rate sensitivity $m$ and of cone angle $\beta$. The same kind of results has been suggested by Storakers [17]. Equation (2) shows that the mean pressure is constant if and only if ratio $h / h$ is constant which agrees with the results of Lucas [12]. An approximation of $\Pi_{\delta}$ is given in reference [13].

\section{$2.2 \quad$ Elastic-viscoplastic solids}

Glassy polymers can be modelled as elastic-viscoplastic solids following a Bingham-Norton law [15]. This assumption seems to be well suited to model the loading part of instrumented indentation experiments [14] on such materials. The parameters of the Bingham-Norton law without strain hardening are 
- Young's modulus : E,

- Poisson's ratio : $\nu$,

- Yield stress at infinitely low strain rate : $Y$,

- Consistency : $K$,

- Strain rate sensitivity : $m$.

For glassy polymers, $Y$ is assumed to be equal to zero. The uniaxial constitutive equations of this model are:

$$
\begin{gathered}
\dot{\varepsilon}^{p}=\left(\frac{\sigma}{K}\right)^{\frac{1}{m}} \\
\sigma=E \varepsilon^{e} \\
\varepsilon=\varepsilon^{e}+\varepsilon^{p}
\end{gathered}
$$

The cone indentation of elastic-viscoplastic solids at constant indentation strain rate has been investigated in a previous paper [13]. They showed that the mean pressure, or indentation hardness, can be expressed starting from a purely elastic state for high indentation strain rates and a purely elastoplastic state for low values. The transition between the two states depends on mechanical properties such as consistency, strain rate sensitivity and Young's modulus and also on cone angle $\beta$. For a Berkovich tip $\left\{\beta=19.7^{\circ}\right\}$ and glassy polymers, we proposed the following approximate expression:

$$
p_{m}=\frac{\Pi_{\delta} K\left(\frac{\dot{h}}{h}\right)^{m}}{1+\frac{5.586}{E *} \Pi_{\delta} K\left(\frac{\dot{h}}{h}\right)^{m}}
$$

where $E *=E /\left(1-\nu^{2}\right)$. Equation above shows that in the limit as $\dot{h} / h \rightarrow 0, p_{m}$ reduces to the mean contact pressure of power law creep solids and in the limit $\dot{h} / h \rightarrow+\infty, p_{m}$ reduces to the mean contact pressure of elastic solids, $p_{m}=E * / 5.586[18]$.

\subsection{Comparison of these two models}

We consider the mechanical properties of PMMA at ambient temperature which has been previously identified by Bucaille [19]. Bucaille showed that for PMMA and Berkovich tips, there 
is no influence of the strain hardening on hardness values. Hence, we do not consider the strain hardening of this material. The corresponding mechanical properties are given in table 1.

\section{[INSERT TABLE 1 ABOUT HERE]}

The curves $p_{m}-\dot{h} / h$ have been computed using equation 2 and 6 and are plotted in figure 1 . It is clearly shown that the viscoplastic assumption can not be used to model the behavior of PMMA in indentation for the common experimental indentation strain rate range. Moreover, we can remark that the error of hardness determination using the viscoplastic assumption increases with the indentation strain rate. When $\dot{h} / h=0.0001 \mathrm{~s}^{-1}$ the error is about $23 \%$ and when $\dot{h} / h=1 s^{-1}$, it is up to $50 \%$. Hence, elastic properties of glassy polymers have to be taken into account to determine time-dependent mechanical properties such as the consistency and the strain rate sensitivity.

\section{[INSERT FIGURE 1 ABOUT HERE]}

\section{Identification of the strain rate senstivity}

\subsection{The viscoplasticity index}

The viscoplasticity index [16] is defined as the slope of graph $\ln \left(p_{m}\right)$ to $\ln (\dot{h} / h)$. It is written

$$
I_{v}=\frac{\partial\left(\ln \left(p_{m}\right)\right)}{\partial\left(\ln \left(\frac{\dot{h}}{h}\right)\right)}
$$

As suggested by Lucas et al [12] and Cheng and Cheng [5], this index is a very good mean to determine the strain rate sensitivity for power law creep solids. Unfortunately, when the indented solid exhibits an elastic-viscoplastic behavior, much attention has to be paid to the interpretation of the viscoplasticity index, because $I_{v}$ varies with $\dot{h} / h$. According to equations (6) and (7), we can write:

$$
I_{v}=m\left(1-\frac{5.586 p_{m}}{E *}\right)
$$

Equation (8) shows that when $\dot{h} / h \rightarrow 0, I_{v}$ reduces to the strain rate sensitivity $m$. In return, when $h / h \rightarrow+\infty, I_{v}$ is quasi-null. Consequently, the viscoplasticity index under-estimates the strain rate sensitivity of the material. To illustrate this, the 
curves $I_{v^{-}} \dot{h} / h$ are plotted in figure 2 in the case of a power law creep solid and in the case of an elastic-viscoplastic solid.

\section{[INSERT FIGURE 2 ABOUT HERE]}

\subsection{A new index to estimate the strain rate sensitivity}

The principle of geometric similarity being satisfied during a cone indentation at constant indentation strain rate, a representative stress $\sigma_{r}$ and a representative strain $\varepsilon_{r}$, characterizing the stress and strain distributions, and corresponding to each other on the uniaxial stress-strain curve can be defined [1][13]. A representative strain rate $\dot{\varepsilon}_{r}$ corresponding to the strain rate of a uniaxial test can thus also be defined. For glassy polymers, the following relation can be applied: $\sigma \propto \dot{\varepsilon}^{m}[20]$. Assuming that the representative strain rate of the indentation test is given by $\dot{\varepsilon_{r}} \propto \dot{h} / h[19]$, it comes:

$$
\sigma_{r} \propto\left(\frac{\dot{h}}{h}\right)^{m}
$$

where $\sigma_{r}$ is the representative stress of the indentation test. Let us now introduce a new index $I_{e v}\{$ called EVP index $\}$

$$
I_{e v}=\frac{\partial\left(\ln \left(\sigma_{r}\right)\right)}{\partial\left(\ln \left(\frac{\dot{h}}{h}\right)\right)}
$$

It is now necessary to estimate representative stress $\sigma_{r}$ of indentation test. Tabor [1] suggested to relate $\sigma_{r}$ to the hardness of the materials:

$$
\sigma_{r}=\frac{p_{m}}{\gamma_{p}}
$$

where $\gamma_{p}$ is a function of the cone angle. For a berkovich indenter, $\gamma_{p}$ is about 2.8. The Tabor's representative stress is well adapted to the indentation of rigid plastic solids. Unfortunately, when elastic deformations are not negligible, this definition does not work. Moreover, we can note that equation (11) leads to $I_{e v}=I_{v}$.

A more general approximate solution to berkovich indentation of elastoplastic solids has been given in a previous paper [11]. It is written:

$$
\sigma_{r}=\frac{0,087 p_{m}}{0,243-0,783 \frac{p_{m}}{E}}
$$


For rigid viscoplastic solids $\left\{p_{m} / E \rightarrow 0\right\}$, the equation (12) reduces to equation 11 with $\gamma_{p}=2.8$. Hence, $I_{e v}$ equals to $I_{v}$ in the case of power law creep solids. For elastic-viscoplastic solids, the definition of representative stress $\sigma_{r}$ given in equation (12) yields to:

$$
I_{e v}=I_{v}\left(1+0,783 \frac{\sigma_{r}}{0,087 E}\right)
$$

Equation (13) shows that the value of $I_{e v}$ cannot be lower than $I_{v}$. Moreover, combining equations (13), (12), (7) and (6), it is easy to show that $I_{e v}$ cannot be greater than strain rate sensitivity $\mathrm{m}$. Hence, we have:

$$
m>I_{e v}>I_{v}
$$

Consequently, the EVP Index is always a better approximation of strain rate sensitivity $m$ than the viscoplasticity index in the case of Bingham-Northon elasticviscoplastic solids. In figure 3, EVP index $I_{e v}$ and viscoplasticity index $I_{v}$ are plotted according to indentation strain rate $\dot{h} / h . I_{v}$ and $I_{e v}$ are computed using equations 6 and 12 and using mechanical properties of PMMA $\{$ table 1$\}$.

\section{[INSERT FIGURE 3 ABOUT HERE]}

\section{Application to nanoindentation experiments}

Nano-indentation tests on PMMA and PC samples have been performed with the help of a Nano-indenter XP $\left\{\operatorname{MTS}^{\circledR}\right\}$. The aim of this experimental work is to show that the EVP index is easy to use on nanoindentation results and that it gives relevant results for these two polymers. No polishing procedure is used on these materials. The roughness of samples, as taken, is below $0.1 \mu \mathrm{m}$ peak to peak. The tests conditions are:

- Continuous Stiffness $\{\Delta \mathrm{h}=1,5 \mathrm{~nm} ; \omega=32 \mathrm{~Hz}\}$

- Max. Load: $15 \mathrm{mN}$

- $\dot{h} / h: 0.0015 s^{-1}, 0.005 s^{-1}, 0.05 s^{-1}$

- Berkovich tip

- 5 tests for each $\dot{h} / h$ 
Oliver and Pharr model [6] is used to estimate the contact area between the indenter and the solid:

$$
h_{c}=h-0.75 \frac{F}{K_{c}}-h_{0}
$$

where $h_{c}$ is the contact depth, $\mathrm{h}$ is the penetration depth, $h_{0}$ is the indenter tip defect, $\mathrm{F}$ is the load applied on the indenter and $K_{c}$ is the contact stiffness. The contact area is given by $A_{c}=24.5 h_{c}^{2}$ and the hardness is computed as $\frac{F}{A_{c}}$. The calibration method of Loubet [7] is employed to avoid thermal drift errors and to estimate $h_{0}$. For such solids, it has been shown that the Oliver and Pharr model gives acceptable values of hardness [21]. The nanoindentation results are summarized in table 2. $\sigma_{r}$ is computed using equation (12). For glassy polymers such as PMMA, the Young's modulus measured by nanoindentation experiments depends on the continuous stiffness frequency [22]. Hence, it does not always correspond to the one which has to be used in equation (12). For this reason, the value proposed by Bucaille [19], E=4200 MPa for PMMA and E=2400 MPa for PC, are used to compute $\sigma_{r}$.

[INSERT TABLE 2 ABOUT HERE]

the curves $p_{m}-\dot{h} / h$ and $\sigma_{r}-\dot{h} / h$ are plotted in graph 4 . The viscoplasticity index and the EVP index are determined by a power law fit of these curves. For PMMA, $I_{v}$ is about $\mathbf{0 . 0 7 7}$ and $I_{e v}$ is about 0.1. The reference value of PMMA strain rate sensitivity is about 0.1 see table 1 \} which agrees well with $I_{e v}$. For PC, it gives 0.039 for $I_{v}$ and 0.053 for $I_{e v}$. According to reference [14], the strain rate sensitivity of $\mathrm{PC}$ is about 0.05 .

[INSERT FIGURE 4 ABOUT HERE]

\section{Discussion}

The experimental results are in good agreement with equation (13) which shows that the value of $I_{e v}$ is greater than the value of $I_{v}$ for elastic-viscoplastic solids. Moreover, we can observe that for PC and PMMA, the value of $I_{e v}$ determined using nanoindentation experiments is very close to the reference values of the strain rate sensitivity. For PMMA, we can remark that the viscoplasticity index leads to an error up to $25 \%$. For these two materials, the EVP index gives thus a better approximation of the strain rate sensitivity than the viscoplasticity index.

The use of $I_{e v}$ is based on the assumption that the indented material follows a BinghamNorton elastic-viscoplastic behavior with $Y=0$. If $Y$ does not equal to $\mathbf{0}$, the development 


\section{Conclusions}

In this paper, it has been shown that the assumption of power law creep solids is not always correct to describe the indentation behavior of time-dependent materials such as glassy polymers. In fact, it is necessary to take into account the influence of elastic properties on instrumented indentation hardness measures. Thus an elastic-viscoplastic formalism seems to be much adapted. Consequently, it points out that viscoplasticity index $I_{v}$, defined only for power law creep solids, may lead to wrong estimations of the strain rate sensitivity.

For this reason, we propose a new index, EVP index $I_{e v}$, which can be used instead of the viscoplasticity index to estimate the strain rate sensitivity. This index is based on a power law fit of the representative stress - indentation strain rate curve. For that, we use a previous work to estimate the representative stress from instrumeted indentation results \{hardness and Young's modulus\}. Obviously, the EVP index will only give an approximation of the strain rate sensitivity. Nevertheless, it is shown theoretically that the estimation of the strain rate sensitivity will be better with $I_{e v}$ than with $I_{v}$. PMMA and PC nanoindentation results are in good agreement with these conclusions.

The use of EVP index is as easy as the use of the viscoplasticity index. It can be employed directly after nanoindentation experiments at different indentation strain rates and it does not require any inverse methods or complex solving operation to obtain a first approximation of the strain rate sensitivity.

\section{References}

[1] D. Tabor, J. App. Phys. 145179 (1971). 
[2] J.L. Loubet,J.M. Georges, and G. Meille, Microindentation techniques in Material Science and Engineering , edited by P.J. Blau and B.R. Lawn (Philadelphia, Pennsylvania: American Society for Testing and Materials,1986) pp 72-89.

[3] R. Hill, B. Storakers, and A.B. Zdunek, Proc. R. Soc. Lond. A 423301 (1989).

[4] M. Dao, N. Chollacoop, K.J. Van Vliet, T.A. Ventakesh, and S. Suresh, Act. Mat. 493899 (2001).

[5] Y.T. Cheng and C.M. Cheng, Mat. Sci. Eng. 4491 (2004).

[6] W.C. Oliver and G.M. Pharr, J. Mat. Res. 71564 (1992).

[7] J.L. Loubet, M. Bauer, A. Tonck, S. Bec, and B. Gauthier-manuel, Mechanical properties and deformation of materials having a ultra-fine microstructures, edited by M.A. Nastasi (Dordrecht: Kluwer, 1993) pp 429-447.

[8] S. Bec, A. Tonck, J.M. Georges, E. Georges, and J.L. Loubet, Phil. Mag. A. 741061 (1996).

[9] R. Hill, The mathematical theory of plasticity, (Oxford Press, 1950).

[10] J.L. Bucaille, S. Stauss, E. Felder, and J. Michler, Act. Mat. 4471663 (2003) .

[11] G. Kermouche, J.L. Loubet, and J.M. Bergheau, Comptes Rendus de Mecanique 333389 (2005).

[12] B. Lucas, W.C. Oliver, G.M. Pharr, and J.L. Loubet, Mater. Res. Soc. Symp. Proc. 436233 (1997)

[13] G. Kermouche, J.L. Loubet, and J.M. Bergheau, Cone indentation of time-dependent materials: the effects of the indentation strain rate, Mech. Mat. Accepted (2005).

[14] J.L. Bucaille, E. Felder, and G. Hochstetter, J. Mat. Sci. 373999 (2001).

[15] J. Lemaitre and J.L. Chaboche, Mechanics of Solid Materials (Cambridge University Press, 1996).

[16] P. Bertrand-Lambotte, J.L. Loubet, C. Verpy, and S. Pavan, Thin Solid Films 398-399 306 (2001).

[17] B. Storakers and P.L. Larsson, J. Mech. Phys. Solids. 42307 (1994).

[18] I.N. Sneddon, Int. J. Engng. Sci. 347 (1965).

[19] J. Bucaille, Simulation numérique de l'indentation et de la rayure des verres organiques., PhD Thesis, Ecole des Mines de Paris (2001).

[20] C. G'sell and J. Jonas, J. Mat. Sci. 14583 (1979).

[21] W.C. Oliver and G.M. Pharr, J. Mat. Res. 193 (2004).

[22] J.L. Loubet, W.C. Oliver, and B.N. Lucas, J. Mat. Res. 151195 (2000). 


\section{List of Tables}

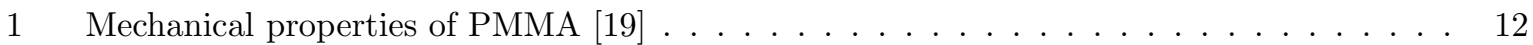

2 Results of nanoindentation on PMMA and PC samples. $\sigma_{r}$ is computed using equation (12) 12

\section{List of Figures}

1 Comparison of PMMA hardness using a viscoplastic model \{power law creep \} and an elastic-viscoplastic model . . . . . . . . . . . . . . . . . . . . . . . . . . . . 13

2 Viscoplasticity index $I_{v}$ versus the indentation strain rate $\dot{h} / h$ for a power law creep solid $\left\{K=205 \mathrm{MPa} . \mathrm{s}^{-1}, m=0.1\right\}$ and for an elastic-viscoplastic solid $\left\{K=205 \mathrm{MPa} . \mathrm{s}^{-1}\right.$,

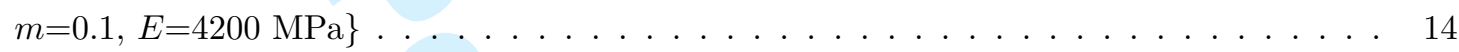

3 Viscoplasticity index $I_{v}$ and EVP index $I_{e v}$ vs $\dot{h} / h$ for an elastic-viscoplastic solid representative of the behavior of PMMA $\left\{K=205 \mathrm{MPa}^{-1}, m=0.1, E=4200 \mathrm{MPa}\right\} \ldots \ldots$

4 Comparison between $I_{v}, I_{e v}$ and strain rate sensitivity $m$ for PMMA and PC, A : determination of $I_{v}$ using a power law fit of the $p_{m}-\dot{h} / h$ curve, B : determination of $I_{e v}$ using a power law fit of the $\sigma_{r}-\dot{h} / h$ curve . 


\begin{tabular}{|ccc|}
$E\{\mathrm{MPa}\}$ & $K\left\{M P a . s^{m}\right\}$ & $m$ \\
\hline 4200.0 & 205.0 & 0.1
\end{tabular}

Table 1: Mechanical properties of PMMA [19]

\begin{tabular}{c|cc|cc|} 
& \multicolumn{2}{|c|}{ PMMA } & \multicolumn{2}{c|}{ PC } \\
$\dot{h} / h$ & $p_{m}$ & $\sigma_{r}$ & $p_{m}$ & $\sigma_{r}$ \\
\hline 0.05 & $287 \pm 5$ & $132 \pm 3.5$ & $204 \pm 1.5$ & $100 \pm 1$ \\
\hline 0.005 & $238 \pm 1$ & $105 \pm 0.4$ & $184 \pm 0.5$ & $87 \pm 0.4$ \\
\hline 0.0015 & $220 \pm 1.2$ & $93 \pm 0.6$ & $178 \pm 1$ & $83 \pm 0.5$
\end{tabular}

Table 2: Results of nanoindentation on PMMA and PC samples. $\sigma_{r}$ is computed using equation (12) 


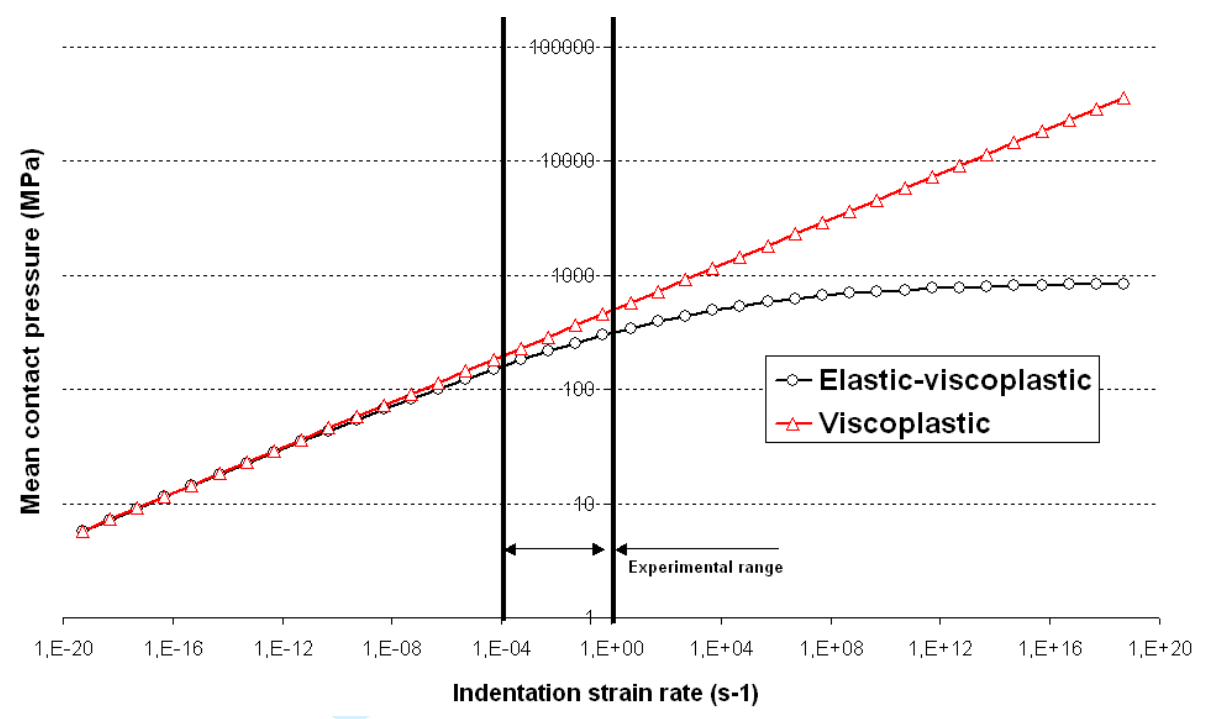

Figure 1: Comparison of PMMA hardness using a viscoplastic model \{power law creep\} and an elastic-viscoplastic model 


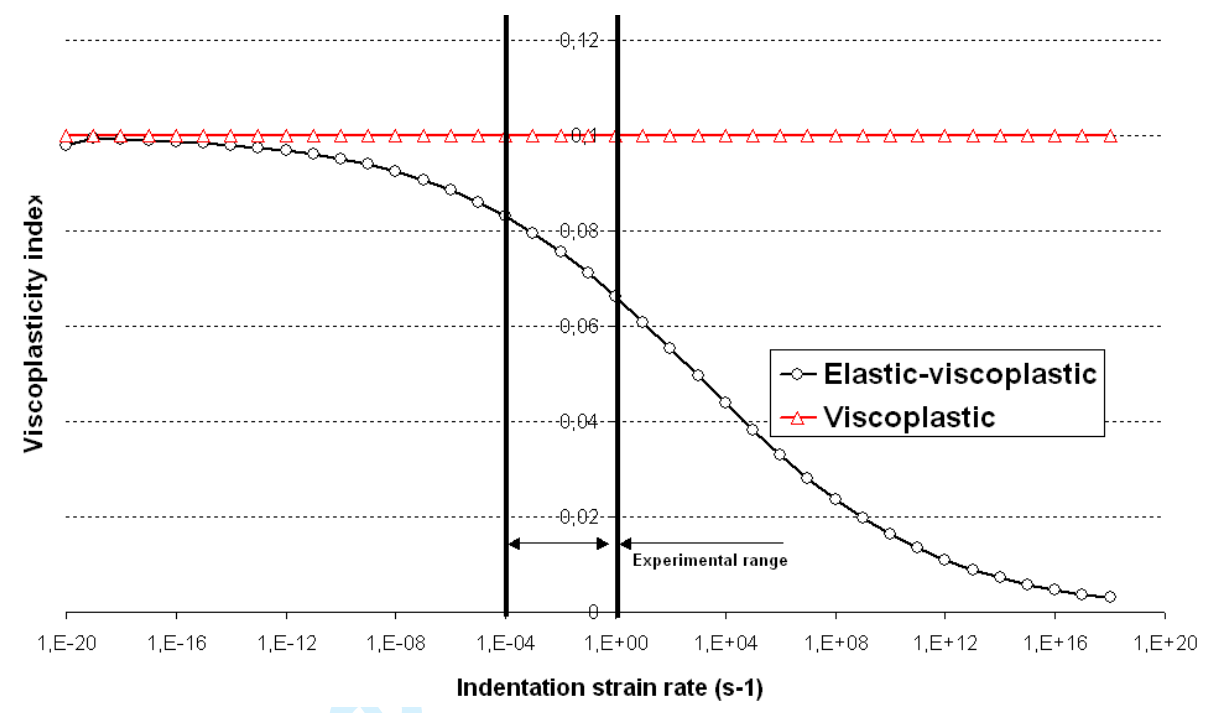

Figure 2: Viscoplasticity index $I_{v}$ versus the indentation strain rate $\dot{h} / h$ for a power law creep solid $\left\{K=205 M P a . s^{-1}, m=0.1\right\}$ and for an elastic-viscoplastic solid $\left\{K=205 M P a . s^{-1}, m=0.1\right.$, $E=4200 \mathrm{MPa}\}$

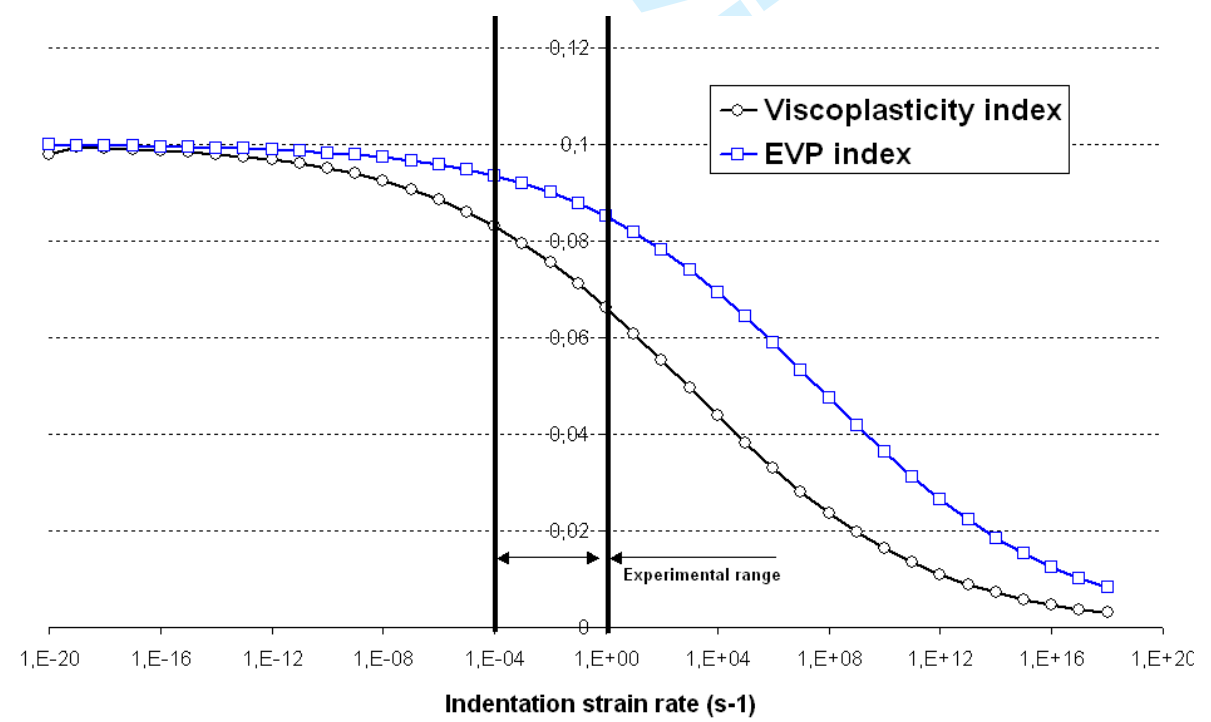

Figure 3: Viscoplasticity index $I_{v}$ and EVP index $I_{e v}$ vs $\dot{h} / h$ for an elastic-viscoplastic solid representative of the behavior of PMMA $\left\{K=205 \mathrm{MPa}^{-1}, m=0.1, E=4200 \mathrm{MPa}\right\}$ 

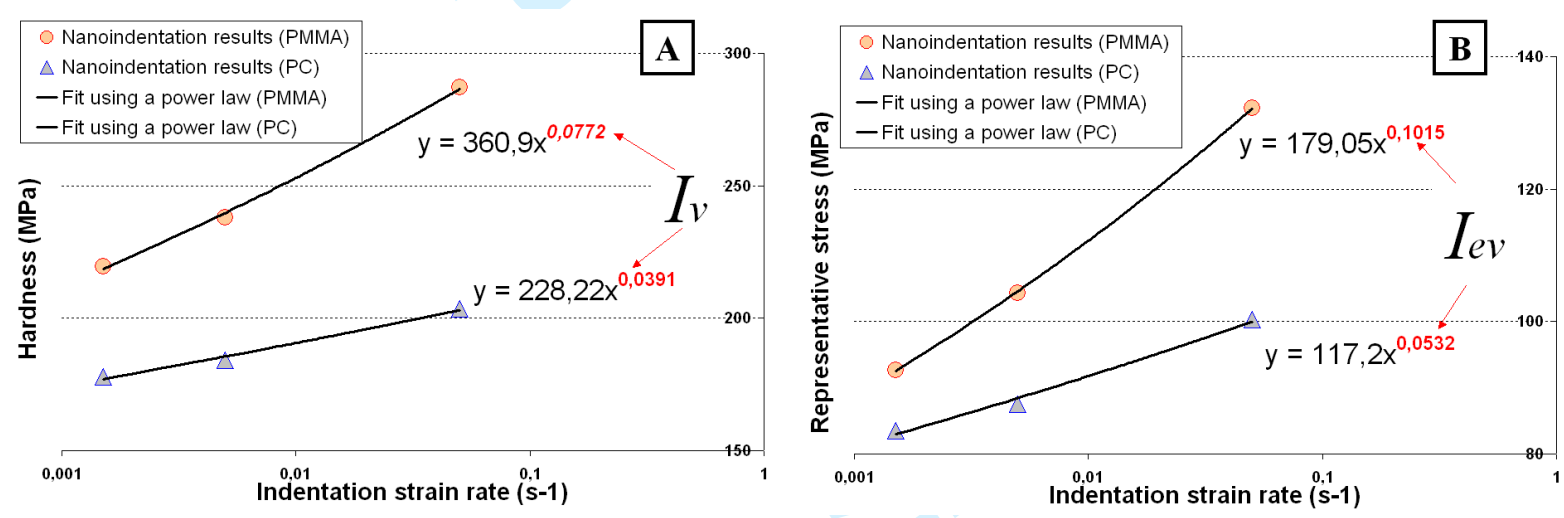

Figure 4: Comparison between $I_{v}, I_{e v}$ and strain rate sensitivity $m$ for PMMA and PC, A : determination of $I_{v}$ using a power law fit of the $p_{m}-\dot{h} / h$ curve, B : determination of $I_{e v}$ using a power law fit of the $\sigma_{r}-\dot{h} / h$ curve 